Objectives We sought to determine if the status (primed/activated) of NADPH oxidase of articular PMN was correlated with rheumatic disease activity and TNF, IL-8 and GM-CSF synovial concentrations.

Methods Knee joint fluid aspiration was performed in 17 patients, 11 with RA and 6 with spondyloarthropathy (SpA). Usual clinical and biological data were recorded for each patient, allowing a DAS28 scoring. NADPH oxidase activity was analysed with cytochrome $\mathrm{c}$ reduction technique. Phosphorylation of p47phox was evaluated with isoelectrofocusing and immunoblotting using a specific antibody. Cytokines concentrations were measured with ELISA kits.

Results NADPH oxidase activity was increased in the majority of RA knee joints, and to a lesser extent in the SpA group. In the RA group, the NADPH oxidase activity was correlated positively with DAS28, with the PMN count in the synovial fluid, with the degree of $\mathrm{p} 47 \mathrm{phox}$ phosphorylation, and with the synovial concentrations of TNF and IL-8. Concentrations of GM-CSF remained very low or undetectable in all patients. In the RA group only, the DAS28, the PMN count and the phosphorylation of p47phox were correlated with synovial concentrations of TNF and IL-8.

Conclusion NADPH oxidase activation, through an increased phosphorylation of p47phox, seems to be implicated in joint inflammation during RA. This phenomenon could be related to high level of TNF and IL-8.

\section{THU0121 BCL-XL AND PLASMA CELL SURVIVAL IN RHEUMATOID SYNOVIUM}

${ }^{1} S$ Busteed, , $\mathrm{MW}$ Bennett, ${ }^{2} \mathrm{M}$ Stone, ${ }^{1} \mathrm{C}$ Molloy, ${ }^{1} \mathrm{~J}$ O'Connell, ${ }^{1} \mathrm{~F}$ Shanahan, ${ }^{3} \mathrm{MG}$ Molloy. ${ }^{1}$ Medicine; ${ }^{2}$ Rheumatology, Toronto Western Hospital, Toronto, Canada; ${ }^{3}$ Rheumatology, Cork University Hospital, Cork, Ireland

\subsection{6/annrheumdis-2001.998}

Background Bcl-xL is a Bcl-2 homologue that regulates lymphocyte apoptosis. It has been reported that co-culture of B cells with rheumatoid synovial stromal cells induces upregulation of Bcl-xL, consequently inhibiting B cell apoptosis. Impaired apoptosis of auto-antibody producing $\mathrm{B}$ cells may contribute to the perpetuation of inflammation in rheumatoid arthritis (RA). The phenotype of synovial $\mathrm{T}$ lymphocytes in $\mathrm{RA}-\mathrm{Bcl}-\mathrm{xL}^{\text {high }} / \mathrm{Bcl}$ $2^{\text {low }}$, may also be linked to the enhanced survival of $\mathrm{T}$ lymphocytes within the joint.

Objectives In this study, we examined the expression of Bcl-xL in rheumatoid synovium using immunohistochemistry.

Methods Sections of synovium were obtained intraoperatively from patients with RA $(\mathrm{n}=18)$. Specimens from patients with osteoarthritis were used as non-inflammatory controls $(\mathrm{n}=9)$. Staining was carried out using a polyclonal rabbit antibody to Bcl-xL. Peripheral blood lymphocytes were used as positive biological controls. Detection of cell death was carried out using the TUNEL assay (terminal deoxynucleotidyl transferase (TdT) mediated dUTP nick end labelling). Identification of plasma cells within the lymphocyte population was performed using a monoclonal antibody to CD138.

Results Bcl-xL was expressed in both RA and OA tissue. Of note, there was a marked infiltrate of $\mathrm{Bcl}-\mathrm{xL}$ positive cells in 13 of the 18 RA sections with scattered positive cells in a further 2 sections. Only 1 of the 9 OA sections demonstrated a similar degree of plasma cell infiltration and Bcl-xL expression, although a few positive plasma cells were noted in the remaining sections.
Plasma cells infiltrates that were Bcl-xL positive were noted to be TUNEL-negative on consecutive sections.

Conclusion Upregulation of Bcl-xL by plasma cells in rheumatoid synovium may prevent their elimination by apoptosis and may play a role in the pathogenesis in rheumatoid arthritis.

\section{THU0122 ANTIOXIDANT VITAMINS AND LIPID PEROXIDATION IN PATIENTS WITH RHEUMATOID ARTHRITIS: ASSOCIATION WITH INFLAMMATORY MARKERS}

S Paredes, J Girona, JC Vallvé, E Hurt-Camejo, M Heras, L Masana. Rheumatology, Hospital Sant Joan, Reus, Spain

\subsection{6/annrheumdis-2001.999}

Background Rheumatoid arthritis (RA) is a chronic inflammatory disease that has been associated with an increase of cardiovascular disease (CVD). However, the mechanism underlying the high incidence of CVD is unclear. It has been postulated that the chronic inflammation associated with RA could lead to an accelerated atherogenesis. Lipid peroxidation and low antioxidants levels are associated with increase of CVD and RA. Furthermore, inflammatory markers and cytokines has related with inflammatory responses and pathogenesis in RA and also atherosclerosis.

Objectives To evaluate in RA patients the vitaminic status and their relation with secretory phospholipase A2 (sPLA2) and other inflammatory markers, and also lipid peroxidation parameters.

Methods The study comprises 30 patients with diagnosed RA according ACR 1987 criteria under treatment and 30 matched controls. Inflammatory markers studied were sPLA2, VCAM, ICAM, TNF $\alpha$, IFN $\gamma$, CRP, ESR and fibrinogen. Lipid profile, size distribution of LDL subclasses and the binding affinity of LDL to chondroitin-6-sulfate glycosaminoglycan (GAG) were analysed. The vitamins $\mathrm{A}$ and $\mathrm{E}$ were determinated in plasma by HPLC. The susceptibility of LDL oxidation was evaluated by the kinetics of conjugated dienes formation induced by hemin. Lag phase (LP), maximal rate of diene production (MR), and maximum diene production (MDP) were studied.

Results RA patients had significant higher plasma levels of sPLA2, VCAM, ICAM, TNFo, IFN $\gamma$, CRP, ESR and fibrinogen compared with controls. LDL cholesterol in patients with RA was lower $(\mathrm{p}<0.05)$. Plasma RA patients had significantly higher levels of small dense LDL and lower levels of large light LDL than controls $(\mathrm{p}<0.01)$. LDL affinity $(\mathrm{Kd})$ to GAG were significantly higher in RA patients than in controls $(p<0.05)$. No differences were observed in vitamins and among the different phases of the dienes formation. In RA patients, a negative correlation between vitamins A and E and sPLA2 ( $p<0.01$ ), as well as between vitamins and $\mathrm{CRP}(\mathrm{p}<0.01)$, was observed.

A positive correlation between Kd LDL and LP $(p<0.05)$ in RA patients was observed.

Conclusion These results suggest that inflammation influences the vitaminic status in RA patients. This alteration combined with the presence of atherogenic small LDL with high affinity for GAG may contribute sinergistically to the higher risk for atherosclerotic CVD reported in RA patients.

\section{THU0123 APOPTOSIS MARKERS IN RHEUMATOID ARTHRITIS}

M Szmyrka, J Szechinski. Rheumatology, Wroclaw University of Medicine, Wroclaw, Poland 